\title{
Human Anti-Anti-Idiotype Antibody
}

National Cancer Institute

\section{Source}

National Cancer Institute. Human Anti-Anti-Idiotype Antibody. NCI Thesaurus. Code C129919.

A human antibody that recognizes human anti-mouse anti-idiotype antibodies. 